International Institute for Applied Systems Analysis - A-2361 Laxenburg - Austria Tel: +432236 807 • Fax: +43223671313 • E-mail: info@iiasa.ac.at • Web: www.iiasa.ac.at

INTERIM REPORT IR-97-069/October

\title{
Risk-based Selection of Forest Regeneration Methods
}

Wenchao Zhou (zhou.wenchao@sekon.slu.se)

\section{Approved by}

Yuri M. Emoliev (emoliev@iiasa.ac.at)

Co-Leader, Risk, Modeling and Policy

Interim Reports on work of the International Institute for Applied Systems Analysis receive only limited review. Views or opinions expressed herein do not necessarily represent those of the Institute, its National Member Organizations, or other organizations supporting the work. 


\section{Contents}

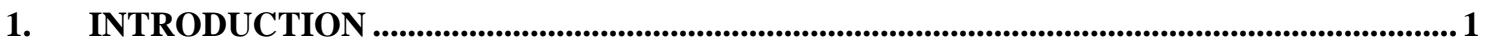

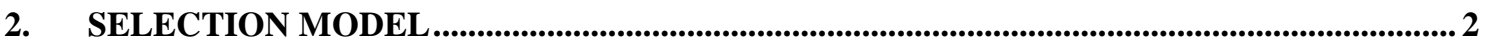

2.1 EVALUATION OF THE PLANTING METHOD ……………............................................................ 3

2.2 EVALUATION OF THE SEED-TREE METHOD .................................................................................

3. CASE STUDY....................................................................................................................................................

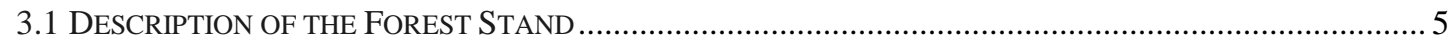

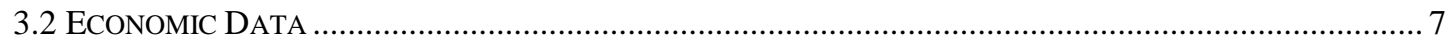

4. RESULTS AND DISCUSSION ...................................................................................................................... 8

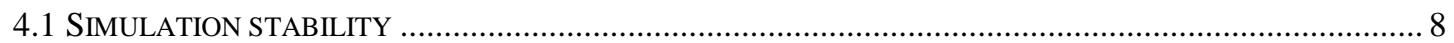

4.2 PREFERRED REGENERATION METHOD AND THE RELATED INTENSITY …......................................... 8

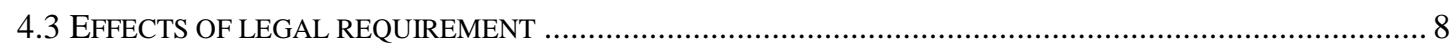

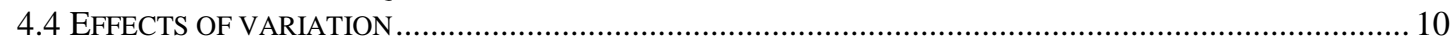

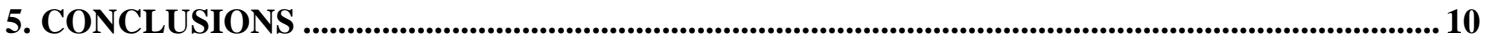




\section{Abstract}

A stochastic optimization model is developed to make a selection between the planting method and the seed-tree method, taking into account the uncertainty of, and the legal requirement on, the stocking level of the established seedlings in a given year after regeneration action. Uncertainty is quantified as the variation of the mortality rate of planted seedlings for the planting method, and as the prediction error for the seed-tree method. The objective of the forest landowner is assumed to maximize the expected net present value (NPV). Numerical simulations show that the owner should prefer the seed-tree method to the planting method for Scots pine stand. However, if the risk-free selection model is used, it overestimates the expected NPV by about $2 \%$. Sensitivity analysis shows that a less restrictive forest act could improve the expected net present value both for the planting method and the seed-tree method. Sensitivity analysis also shows that decreasing the level of variation of the mortality rate (or prediction error) increases the expected NPV.

Keywords: uncertainty, stochastic optimization, planting method, seed-tree method, legal requirement 


\section{Acknowledgments}

The study was conducted when the author participated in the Young Scientists' Summer Program (YSSP) at the Risk, Modeling and Policy Project of the International Institute for Applied Systems Analysis (IIASA), Laxenburg, Austria.. The author would like to thank Dr. Yuri Ermoliev for his academic guidance during the period of the author's YSSP studies. Special thanks go to his supervisor, Associate Professor Peter Lohmander, and Assistant Professor Gong Peichen at the Department of Forest Economics, the Swedish University of Agricultural Sciences, for their valuable comments on the paper. This study was funded by the Swedish Council for Planning and Coordination of Research (FRN), and by the Swedish Council for Forestry and Agricultural Research (SJFR). 


\section{About the Author}

Wenchao Zhou graduated from the Beijing Forestry University in 1990. He is currently a doctoral student in forest economics and management at the Swedish University of Agricultural Sciences, Department of Forest Economics, Umea, Sweden. The subject of his studies is Optimal Forest Regeneration. He participated in IIASA's Young Scientists Summer Program in 1997. 


\title{
Risk-based Selection of Forest Regeneration Methods
}

\author{
Wenchao Zhou
}

\section{Introduction}

Forest landowners are faced with the decision of selecting one regeneration method and the related intensity for the site on which they plan to harvest the standing trees. For the regeneration outcomes in Swedish forestry, one official examination is made on the site when the new trees reach a particular age. If the number of the well-distributed seedlings is found to be below the level of legal requirements, the owner has to supplement or replant the land (The Forest Act-Manual, Sweden, 1994). There are two methods commonly used in Swedish forestry: the planting method, which is on the dominant position, and the seed-tree method, which is increasingly practiced (Nordlund, 1996). For the planting method, the owner can control how many seedlings per hectare to plant, but he is not able to know for sure how many of those could survive to the examination year. For the seed-tree method, the owner can control the number of seedtrees used for producing seedlings, but he is not able to know for sure how many seedlings per hectare could be produced up to the examination year. Thus, no matter which of the two methods is selected, the owner has to face the uncertainty. In other words, the selection of regeneration methods involves risks.

An economic comparison was made by Dangerfield \& Edwards(1991) between natural and planted regeneration of Loblolly pine under deterministic case. They found that natural loblolly regeneration is financially competitive with planted regeneration. Several authors have developed models to determine the economic optimum planting density with consideration for the variation of timber prices (Gong 1995, Mörling 1995, Taylor \& Fortson 1991, etc.), and for both the survival probability and the timber price 
variation (Lohmander 1994). The optimal seed-tree density in northern Sweden was studied under certainty by Zhou (1996). These models, however, did not consider the legal requirement on the minimum level of the established seedlings. If considered, it is possible that a significant change of the solutions could occur. Thus, work is needed to uncover the implications of the legal requirement on the selection of regeneration methods and the economic return. In this paper, the legal requirement is incorporated into the selection model as one necessary constraint.

The aim of this study is to develop an approach (1) to select from the planting and the seed-tree methods the economically preferred one when the mentioned uncertainty and legal requirements are taken into account; (2) to identify the optimal regeneration intensity for the preferred method.

The selection is achieved by calculating the maximum expected net present value (NPV) for each of the two methods by solving stochastic optimization models and selecting the one that produces the greater expected NPV. To focus on the effects of the uncertainty in the level of the established seedlings, I consider such uncertainty the only source of risk. The uncertainty is quantified as the variation of the mortality rate of the planted seedlings for the planting method, and as the prediction error for the seed-tree method. In addition, an attempt is made to uncover the implication of the legal requirement on the financial returns.

In Section 2 the selection model is discussed. The resulting stochastic optimization problem can be generalized to include more decision variables. Section 3 deals with a case study for Scots pine stand, and the solutions are presented in Section 4. Finally, the paper has a conclusion section.

\section{Selection Model}

To begin with, consider an even-aged stand with a state vector $I_{0}$. The stand is harvested in the current year. The site condition is suitable for the planting or seed-tree method. Official examination takes place after $T$ growing seasons. The number of the well-distributed seedlings required is denoted by $N L$. The objective of the forest owner is to select one of the two regeneration methods and the related regeneration intensity ${ }^{1}$

\footnotetext{
${ }^{1}$ In this paper, the regeneration intensity is defined as the number of planted seedlings per hectare for the planting method, or the number of seed-trees per hectare for the seed-tree method.
} 
to maximize the expected NPV of the financial returns from the current and future harvests.

To focus the attention on the effects of the uncertainty in the stocking levels in the examination year, I assume that the uncertainty of the stocking levels is the only source of risk, any other sources of risk, such as timber price variation and timber yield variation, are ignored.

\subsection{Evaluation of the planting method}

Let $X$ denote the set of feasible planting densities for the planting method, the number of the planted seedlings per hectare survival to growing season $T, s p$, is estimated by ${ }^{2}$

$$
s p=x \cdot(1-m) \quad x \in X
$$

where $x$ is the initial planting density, $m$ is the mortality rate of the planted seedlings, which is a normally distributed $N\left(\bar{m}, \sigma^{2}\right)$ random variable, assuming that both $\bar{m}$ and $\sigma$ are independent of $x$.

We now turn to the formulas for calculating the financial return. For a given initial planting density $x$, let $m_{i}$ denote the $i$ th value selected at random from the distribution of $m$, and define the number of the survival trees per hectare after $T$ growing seasons, $s p_{i}$, as scenario $i$. Then, the NPV of the newly planted stand associated with scenario $i, \pi_{i}^{p}(x)$, could be calculated by

(2) $\pi_{i}^{P}(x)=\left\{\begin{array}{lrr}\max _{t \in\left[T_{\min }, T_{\max }\right]}\left\{-C(x)+\left[R\left(s p_{i}, p s(t), t\right)+L\right] \cdot e^{-r t}\right\} & \text { if } & s p_{i} \geq N L \\ \max _{t \in\left[T_{\min }, T_{\max }\right]}\left\{-C(x)-C\left(x_{T}\right) e^{-r T}+[R(N L, p s(t), t)+L] \cdot e^{-r t}\right\} & \text { if } & s p_{i}<N L\end{array}\right.$ where $C(\cdot)$ is the regeneration cost; $R(\cdot)$ is the net revenue from harvesting the newly planted stand in the future; $p s(t)$ is the stumpage price, dependent on the stand state and timber prices at age $t ; r$ is the interest rate; $L$ is the bare land value after harvest, which is assumed to be known; $x_{T}$ is the number of the seedlings needed to supplant ${ }^{3}$ at $T$ when

\footnotetext{
${ }^{2}$ The estimation should be conditional on the site condition, which, for simplicity, is not explicitly printed in all the equations or functions within this paper.

${ }^{3}$ It is possible that the level of seedlings still does not satisfy the legal requirement. For tractability, that possibility is ignored.
} 
$s p_{i}<N L ; T_{\min }$ and $T_{\max }$ are the minimum and maximum harvest age required, respectively.

Let $K$ denote the number of scenarios ${ }^{4}$, then the expected NPV of newly planted stand associated with $x, E\left[\pi^{P, K}(x)\right]$, is approximated by the sample mean

$$
E\left[\pi^{P, K}(x)\right] \approx \frac{1}{K} \sum_{i=1}^{K} \pi_{i}^{P}(x)
$$

To obtain the maximum financial return for the planting method, we maximize

$$
\pi^{P, K}=\max _{x \in X}\left\{E\left[\pi^{P, K}(x)\right]+\pi_{0}\left(I_{0}\right)\right\}
$$

where $\pi_{0}(\cdot)$ is the financial return from harvesting the current stand. This is a stochastic optimization problem, which is solved by using the sample mean approximation (3).

\subsection{Evaluation of the seed-tree method}

Let $Y$ denote the set of feasible seed-tree densities for the seed-tree method. Then the number of the seedlings produced per hectare after $T$ growing seasons, $s s$, is estimated by function

$$
s s=s(y)+\varepsilon(y) \quad y \in Y
$$

where $y$ is the number of seed-trees per hectare, and $\varepsilon$ is a normally distributed $N\left(0, \omega^{2}\right)$ random variable, conditional on the density of seed-trees ${ }^{5}$.

We now evaluate the financial return for the seed-tree method. For a given number of seed-trees $y$, let $\varepsilon_{i}$ denote the $i$ th value selected at random from the distribution of $\varepsilon$, then the number of the established seedlings per hectare after $T$ growing seasons, $s s_{i}$, is determined by

$$
s s_{i}=s(y)+\varepsilon_{i}
$$

The NPV of the new stand associated with scenario $i, \pi_{i}^{S}(y)$, could be calculated by

\footnotetext{
${ }^{4}$ The accuracy of the approximation depends on the number of scenarios.

${ }^{5}$ Hagner (1962) showed that the prediction error decreases as the density of regeneration increases.
} 
(7)

$$
\pi_{i}^{S}(y)= \begin{cases}\max _{t \in\left[T_{\min } T_{\max }\right]}\left\{-C^{S}+\left[R\left(s s_{i}, p s(t), t\right)+L\right] \cdot e^{-r t}\right\} & \text { if } \quad s s_{i} \geq N L \\ \max _{t \in\left[T_{\min }, T_{\max }\right]}\left\{-C^{S}-C\left(x_{T}\right) e^{-r T}+[R(N L, p s(t), t)+L] \cdot e^{-r t}\right\} & \text { if } s s_{i}<N L\end{cases}
$$

where $C^{S}$ is the cost of the site preparation such as soil scarification.

Let $K$ denote the number of scenarios, then the expected NPV from the newly produced stand associated with $y, E\left[\pi^{S, K}(y)\right]$, is approximated by

$$
E\left[\pi^{S, K}(y)\right] \approx \frac{1}{K} \sum_{i=1}^{K} \pi_{i}^{S}(y)
$$

To obtain the maximum financial return for the seed-tree method, we maximize

$$
\pi^{S, K}=\max _{y \in Y}\left\{\mathrm{E}\left[\pi^{S, K}(y)\right]+\pi_{0}\left(y ; I_{0}\right)+\pi_{1}\left(y ; I_{0}, T_{s}\right) \cdot e^{-r T_{s}}\right\}
$$

where $\pi_{0}(\cdot)$ is the financial return from harvesting the current stand, and $\pi_{1}(\cdot)$ is the financial return from the removal of the seed-trees after $T_{s}$ years. The resulting stochastic optimization problem is again solved by using the sample mean approximation (8).

Finally, the preferred regeneration method could be determined by simply selecting the one that realizes the greater maximum expected NPV.

\section{Case Study}

\subsection{Description of the Forest Stand}

For the case study, I considered only one productivity site class for Scots pine (Pinus sylvestris). The site is selected from the study by Ackzell (1994). A detailed description of the site condition can be found in Ackzell (1994). Briefly, the site is located in northern Sweden, near Lake Storsandsjö, latitude N 64 ${ }^{\circ} 18^{\prime} 35^{\prime \prime}$, longitude E1946'10", altitude $280 \mathrm{~m}$ above sea level. The site index is T206 , and the site was judged to be suitable for the planting or the seed-tree method. Because no data about the state of the former stand before harvest are obtained, assume that it is characterized by stand age:

\footnotetext{
${ }^{6}$ Dominant height of Scots pine at an age of 100 years is $20 \mathrm{~m}$.
} 
80 years; dominant height: $17.8 \mathrm{~cm}$; density: 534 trees/ha; average tree diameter: 23.9 $\mathrm{cm}$; basal area: $23.9 \mathrm{~m}^{2} / \mathrm{ha}$, and standing timber volume: $198 \mathrm{~m}^{3} / \mathrm{ha}$. The data are taken from the yield table published by Persson (1992). Referring to the Swedish Forest Act (1994), the minimum number of well-distributed seedlings required for the site is $(N L=) 1300$ trees/ha. An experiment by Ackzell (1994) on the site specified that the mean mortality rate of the planted seedlings after 10 years growing seasons was $(\bar{m}=) 0.27$ and the standard deviation was $(\sigma=) 0.057$.

It is common in northern Sweden to scarify the soil in order to create good condition for seedling establishment when the seed-tree method is implemented. Assuming that a total of 2500 patches per hectare with an average size of $0.53 \mathrm{~m}^{2}$ are scarified, the total cost for the site preparation is about $\left(C^{S}=\right) 2400$ SEK/ha (Westerberg, 1996) in 1990's value.

A linear function developed by Hagner (1962) is used to project the stocking levels established by the seed-tree method. The prediction error component of the function in the report is expressed in the form of dispersion in per cent of dispersion of the mean value. Because no detailed explanation about the "dispersion" is available, I choose 30 sample stands, which fit the application limits on the function, from the data set published by Hagner (1962) to estimate the prediction error in the form of standard deviation. Since the prediction error is related to the seed-tree density (Hagner, 1962), I group the seed-tree density into two intervals, 50-100 and 101-150 trees/ha, and then estimate the standard deviation within each interval. When specified to the site condition and expressed as the number of seedlings per scarified patch, the function is written as

$$
\text { ss }=0.01328772 \cdot y .
$$

The standard deviation of the prediction error is $(\omega=) 0.35$ seedlings/patch for seed-tree densities between 50 and 100 trees/ha, and 0.28 seedlings/patch between 100 and 150 trees/ha. In addition, the simulation is based on the following assumptions. The seedtrees are removed after $\left(T_{s}=\right) 10$ years with $10 \%$ seedlings being damaged. Examination takes place at the year after $(T=) 10$ growing seasons.

Regarding the regeneration intensity, the simulation considers planting density $x$ from 1300 to 2500 seedlings/ha in 50 seedlings/ha intervals, and seed-tree density $y$ from 50 
to 150 trees/ha in 10 trees/ha intervals. The states of the stand are projected using the functions of Pettersson (1992) and Persson (1992). In practice, the seed-tree density affects the growth conditions (grass, water and light, etc.) available to the new seedlings, and further affects the development of the newly produced stand. The study by Hagner (1962) showed that the height development of the seedlings was inhibited by the seed-trees, especially, in the situation of high density. Such impacts are not considered in this study, but this does not mean that the impacts are not important for evaluating the seed-tree method.

\subsection{Economic Data}

Economic data and functions used for the simulation are listed in Table 1. The estimations of economic returns are calculated from two timber products: sawtimber and pulpwood. The yield of each product and the stumpage prices are estimated using equations given by Gong (1995).

Table 1. Economic data and functions for the simulation

\begin{tabular}{|c|c|c|c|}
\hline Name & Value/Function & Unit & Source \\
\hline \multicolumn{4}{|l|}{ Cost } \\
\hline Planting $^{7}$ & $C(x)=1600+2.64 \cdot x$ & SEK/ha & Gong, 1995 \\
\hline Final harvesting & $C_{f}(V)=1765+92.3 \cdot V$ & SEK/ha & \\
\hline Cutting seed-trees & $C_{S T}(V)=1765+152.1 \cdot V$ & SEK/ha & \\
\hline $\begin{array}{l}\text { Site preparation for } \\
\text { Seed-tree method }\end{array}$ & $C^{S}=2400$ & SEK/ha & $\begin{array}{l}\text { Westerberg, } \\
1996\end{array}$ \\
\hline \multicolumn{4}{|l|}{ Timber prices ${ }^{8}$} \\
\hline Sawtimber & $P_{\mathrm{s}}=506.82$ & $\mathrm{SEK} / \mathrm{m}^{3}$ & Gong, 1995 \\
\hline Pulpwood & $P_{\mathrm{p}}=222.41$ & $\mathrm{SEK} / \mathrm{m}^{3}$ & \\
\hline Bare land Value & $L=1500$ & SEK/ha & Gong, 1997 \\
\hline Interest rate & $\mathrm{r}=3 \%$ & & \\
\hline
\end{tabular}

\footnotetext{
${ }^{7}$ The economic data given by Gong (1995) was in 1990's value.

${ }^{8}$ The timber prices are no net prices. The calculation of the net price could be found from Gong (1995).
} 


\section{Results and Disc ussion}

\subsection{Simulation stability}

To investigate the stability of the simulation solutions, I first run the model three times by setting scenario number $k$ to be 100,500 and 1000, respectively. It is found that when the scenario number $K$ is set to be 1000 , the simulation solutions approach is stable both for the planting and the seed-tree methods. Accordingly, 1000 scenarios are used for the simulations. Figure 1 shows the relationship between the financial return and the regeneration intensity.

Looking closer at Figure 1(A), we observe that the plot of the financial return against the planting density is $S$-shaped in the domain of the feasible planting densities. This observation is of value to practical forestry. The forest owners who prefer to use the planting method should avoid selecting the planting density at the lowest-return point B shown in Figure 1(A), which is located somewhere between the level of legal requirement and the level of the optimum density. Since the density level at that point is slightly higher than the level of legal requirement, it is highly likely to be chosen as the planting density in practical forestry.

\subsection{Preferred regeneration method and the related intensity}

Now it is time to answer the question which of the two methods is preferred. Figure 1(A) indicates that the optimal planting density is 1900 seedlings/ha, and the accompanying expected NPV is 33658.51 SEK/ha. Figure 1(B) indicates that the optimal seed-tree density is 70 trees/ha, and the accompanying expected NPV is 35856.39 SEK/ha, which is $6.5 \%$ greater than the counterpart of the planting method (33658.51 SEK/ha). Thus, it is evident that the seed-tree method is preferred to the planting method on the test site.

\subsection{Effects of legal requirement}

Sensitivity analysis is conducted to investigate the effects of the changes in the level of legal requirements on the selection of regeneration methods, the economic return, and the optimum intensity. The simulation is repeated with the base level of the legal requirement of 1300 seedlings/ha, plus or minus 300 seedlings/ha. We can observe from Figure 2 that decreasing the level of the legal requirement increases the expected NPV regardless of the regeneration methods. For example, reducing the level of the legal 
requirement from 1300 seedlings/ha (baseline) to 1000 seedlings increases the economic return from 33658.51 to $34592.61 \mathrm{SEK} / \mathrm{ha}(+2.8 \%)$ ) for the planting method, and from 35856.39 to $35993.23 \mathrm{SEK} / \mathrm{ha}(+0.4 \%)$ for the seed-tree method. In contrast, increasing the level of the legal requirement decreases the expected NPV. For example, increasing the level of the legal requirement from 1300 seedling/ha (baseline) to 1600 seedlings/ha decreases the economic return from 33658.51 to 32795.32 SEK/ha (-2.6 \%) for the planting method, and from 35856.39 to 35673.80 SEK/ha $(-0.5 \%)$ for the seed-tree method. The percentages in the parenthesis show that the effects of changing the level of the legal requirement on the financial return are relatively greater in the planting case than in the seed-tree case.

Figure 2 shows that the seed-tree method produces a higher financial return than the planting method at any given level of legal requirements. Furthermore, we can note that the relative difference between the expected NPVs increases with the level of the legal requirement. This trend means that the higher the level of the legal requirement, the more the seed-tree method is preferred to the planting method. This may be explained as follows. At a higher level of the legal requirement, if the forest landowner selects the planting method, he has to plant more seedlings in order to satisfy the legal requirement. As a result, more regeneration cost will be caused. However, if he selects the seed-tree method, he can utilize the probability of more seedlings being naturally produced to satisfy the legal requirement. Since the level of the legal requirement has only slight impacts on the optimal seed-tree density (shown in Figure 3), increasing the level of the legal requirement does not lead to a significant increase in opportunity cost. Therefore, the seed-tree method is more preferred to the planting method with the increase of the level of the legal requirement.

For the optimal regeneration intensity, Figure 3 indicates that changing the level of the legal requirement has significant impacts on the optimal planting density, but slight impacts on the optimal seed-tree density. For example, when decreasing the level of legal requirement from 1300 seedlings/ha (baseline) to 1000 seedling/ha, the optimal planting density reduces from 1900 to 1500 seedlings/ha $(-21.1 \%)$. However, the optimal seed-tree density at different levels of the legal requirement is only slightly different.

In order to calculate the loss in the expected NPV caused by the legal restriction, I run the model with legal requirement free. The results are plotted in Figure 1 and 2. The 
financial loss is $-6.1 \%$ for the planting method, and $-0.8 \%$ for the seed-tree method. The percentages also support the observation mentioned earlier that the legal restriction has a greater impact on the financial return in the planting case than in the seed-tree case. Now one question may be asked. Should it be recommended that the policy authority relaxes the legal requirement? This question will be discussed in the concluding remarks.

\subsection{Effects of variation}

To investigate the effects of the level of the uncertainty on the selection of regeneration methods, the optimum intensity, and the economic return, simulations are repeated with double and half of the risk level of baseline. Figure 4 indicates that decreasing the level of risk increases the economic return. For example, by half the level of risk, the expected NPV increases from 33658.51(baseline) to $33854.48 \mathrm{SEK} / \mathrm{ha}(+0.6 \%)$ for the planting method, and from 35856.39 (baseline) to 36221.84 SEK/ha (1\%) for the seedtree method. It should be noted that at half (or double) the baseline risk level, the expected NPV of the seed-tree is greater than the expected NPV of the planting method. Therefore, the seed-tree method is the preferred choice.

In order to check the economic gain by using the risk-based selection model rather than the risk-free model, I run the model by setting the level of risk to zero. The results are plotted in Figure 3. It could be noted that even in the case of the risk-free model, the seed-tree method still is the preferred method. However, the economic return of the seed-tree method calculated by the risk-free model is higher than the economic return of the seed-tree method calculated by the risk-based model. The relative difference between the expected NPV (36540.56 SEK/ha) of the seed-tree method in the risk-free model and the NPV (35856.39 SEK/ha) of the seed-tree method in the risk-based model is $2 \%$. Thus, an overestimation in the NPV could happen when the risk-free model is used to select the regeneration method.

\section{Conclusions}

This paper applies a risk-based model to selecting one regeneration method for the site on which the owner plans to cut the standing trees in the current year. The selection is achieved by simply comparing the expected NPVs associated with each of the regeneration methods by solving stochastic optimization problems. The case study 
shows that the seed-tree method is preferred for the site for Scots pine. However, the expected NPV calculated by the risk-based model is lower than the expected NPV calculated by the risk-free model. The overestimation in the risk-free model is $2 \%$. Since the comparison is performed only on the test site for Scots pine, the result is, to a great extent, site-, and species-specific. Although more general conclusions should be made until comparisons are made on other sites, we conclude so far that the uncertainty of the stocking levels should be incorporated into the selection model for the proper regeneration method, otherwise, it is possible that an overestimation in the economic return could occur on some sites.

The sensitivity analysis conducted in this study shows that a less restrictive forest act would improve the expected net present value. This observation is supported by the conclusion given by Gong (1995) that the optimal planting densities for Scots pine plantation in northern Sweden are rather low. Gong (1995) found that the optimum planting density is 670 seedlings/ha on the site (T20) for Scots pine in northern Sweden. The optimum density of 670 seedling/ha is much lower than the level of the legal requirement (1300 seedlings/ha) on the site. Lohmander (1994) also concluded that in plantation forestry the economically optimal investment intensity often is very low. Should it therefore be recommended that policy authorities should relax the level of the requirement on the established seedlings. Several studies (Persson, 1976; Johansson, 1992, etc.) showed that the timber quality might be considerably improved by reducing the initial spacing. Due to lack of empirical data, this study has not considered the impacts of the planting density on the timber quality and value in the future. Thus, more work needs to be done until we get an answer to the posed question.

That the seed-tree method is preferred to the planting method is much more species-, site-, and function-specific. The purpose of this study is not to provide a final verdict on which method should be applied in practical forestry. The purpose is to present a methodology for aiding the owners to select a preferred method. From that point of view, the present model is general. Users should insert the parameters collected on the specific site. In addition, the simulation is based on the assumption that the variation of the mortality rate of seedlings (planting method) and prediction error (seed-tree method) follows a normal distribution. In case this assumption is rejected, the proper distribution function should be inserted. 
This study considers the uncertainty in the regeneration outcomes as the only source of risk. Previous studies show that utilizing the variation of timber prices could significantly increase financial returns (Lohmander 1987, Brazee and Mendelson 1988, etc.) when stochastic prices follow a stationary process. Therefore, it is important to extend the model to incorporate the variation of timber prices for selecting the proper regeneration method.

\section{References}

Ackzell, L., 1994. Forest regeneration by nature and man. Dissertation, Swedish University of Agricultural Sciences.

Brazee, R., and R. Mendelsohn. 1988. Timber harvesting with fluctuating prices. Forest Sciences. 34:359-272.

Dangerfield, C. M., Edwards, M. B., 1991. Economic comparison of natural and planted regeneration of Loblolly pine. Southern Journal of Applied Forestry 15: 125-127.

Gong, P. 1995. Regeneration decision and land expectation value: Numerical results of decision model evaluation and optimization. WP-219. Department of Forest Economics, Swedish University of Agricultural Sciences.

Hagner, S., 1962. Natural regeneration under shelterwood stands. The Forest Research Institute of Sweden. Report No 52(4). 263 P.

Johansson, K., 1992. Effects of initial spacing on the stem and branch properties and graded quality of Picea abies (L.) Kars. Scandinavian Journal of Forest Research. 7:503514.

Lohmander, P. 1987. The economics of forest management under risk. Rep. 79, Department of Forest Economics, Swedish University of Agricultural Sciences, S-901 83, Umea, Sweden. 
Lohmander, P. 1994. The economically optimal number of plants, the damage probability and the stochastic roundwood market. Proceedings of the International Symposium on Systems Analysis and Management Decision in Forestry (Gonzalo L. Paredes V. editor.). PP. 290-314.

Mörling, T. 1994. Optimal planting density under price risk. Scandinavian Forest Economics (35): Proceedings of the Biennial Meeting of the Scandinavian Society of Forest Economics (Helles F and Linddal M. eds). pp. 175-183.

Nordlund, S. 1996. Logging technology and methods: trends in large-scale forestry. Results No.2, SkogForsk.

Persson, O. A. 1992. En Produktionsmodell för tallskog i Sverige. Report 31. Department of Forest Yield Research, Swedish University of Agricultural Sciences.

Persson, A. 1976. The influence of the spacing on the quality of sawn timber from Scots pine. Department of Forest Yield Research, Royal College of Forestry, Stockholm. Research Notes 42, 122 pp. (In Swedish with English summary.)

Pettersson, N. 1992. Inverkan av planteringsförbandet på volym och strukture i tall-och granbestånd. Report 30. Department of Forest Yield Research, Swedish University of Agricultural Sciences.

The National Board of Forestry, Skogsvårdslagen Handbook, (The forest act - manual), Värnamo, Sweden, 1994.

Taylor R. G. and Fortson J. C., 1991. Optimum plantation planting density and rotation age based on financial risk and return. Forest Science, 37(3): 886-902.

Westerberg, D. and Hofsten, H., 1996. Scarification under shelterwood. Resultat Nr. 8. SkogForsk.

Zhou, W. 1996. Optimal natural regeneration with seed-trees. Proceedings of the Biennial Meeting of the Scandinavian Society of Forest Economics. 


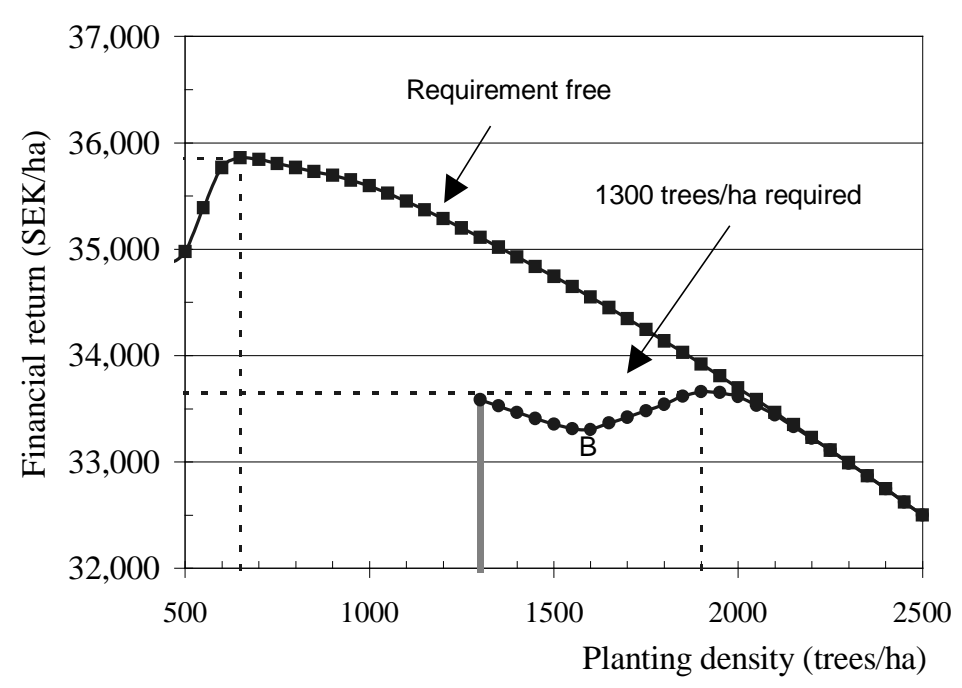

A: Planting method

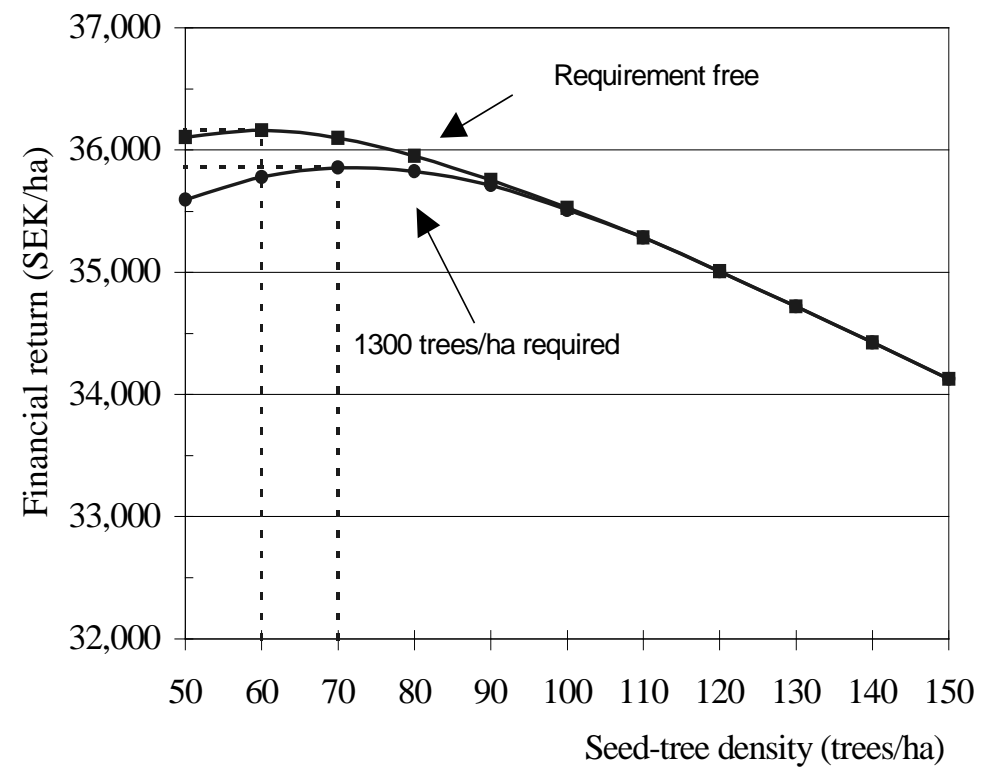

B: Seed-tree method

Figure 1. Financial return as a function of the regeneration intensity with and without legal requirement. 


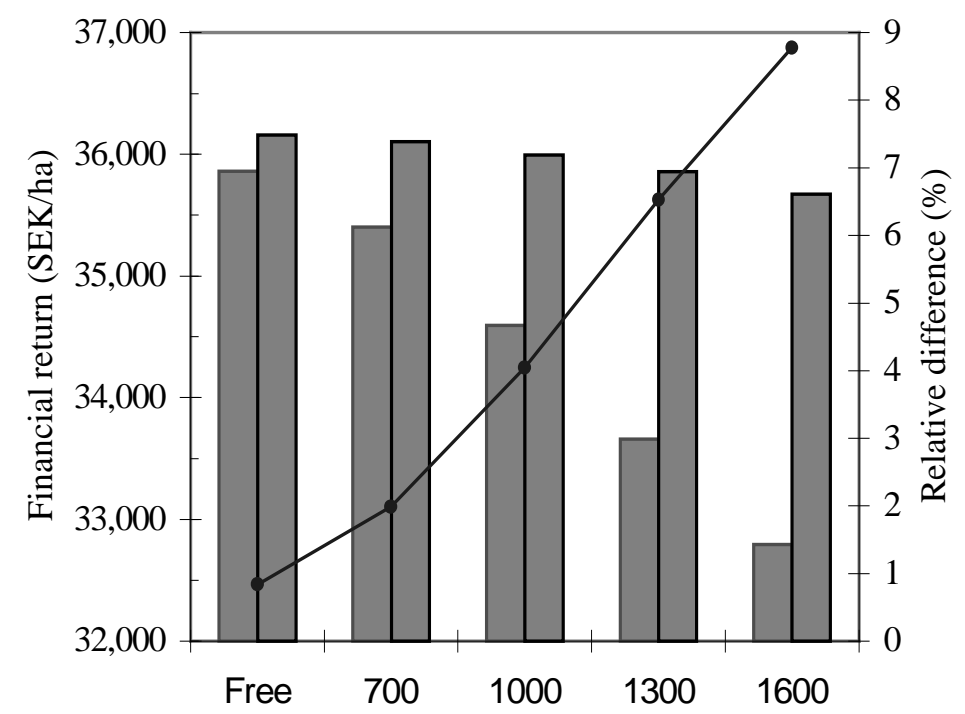

$\square$ Planting method $\square$ Seed-tree method $\rightarrow$-Relative difference

Figure 2. Impacts of legal requirement on the fincancial return

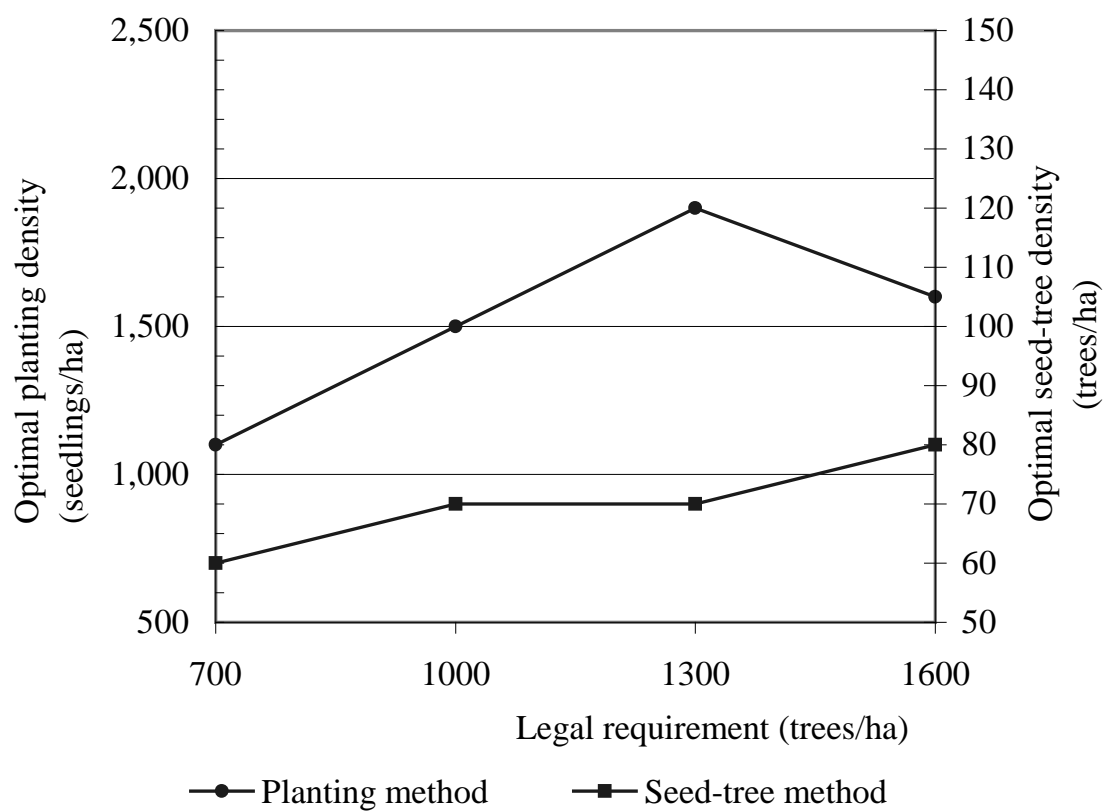

Figure 3. Impacts of the level of legal requirement on the optimal regeneration intensity 


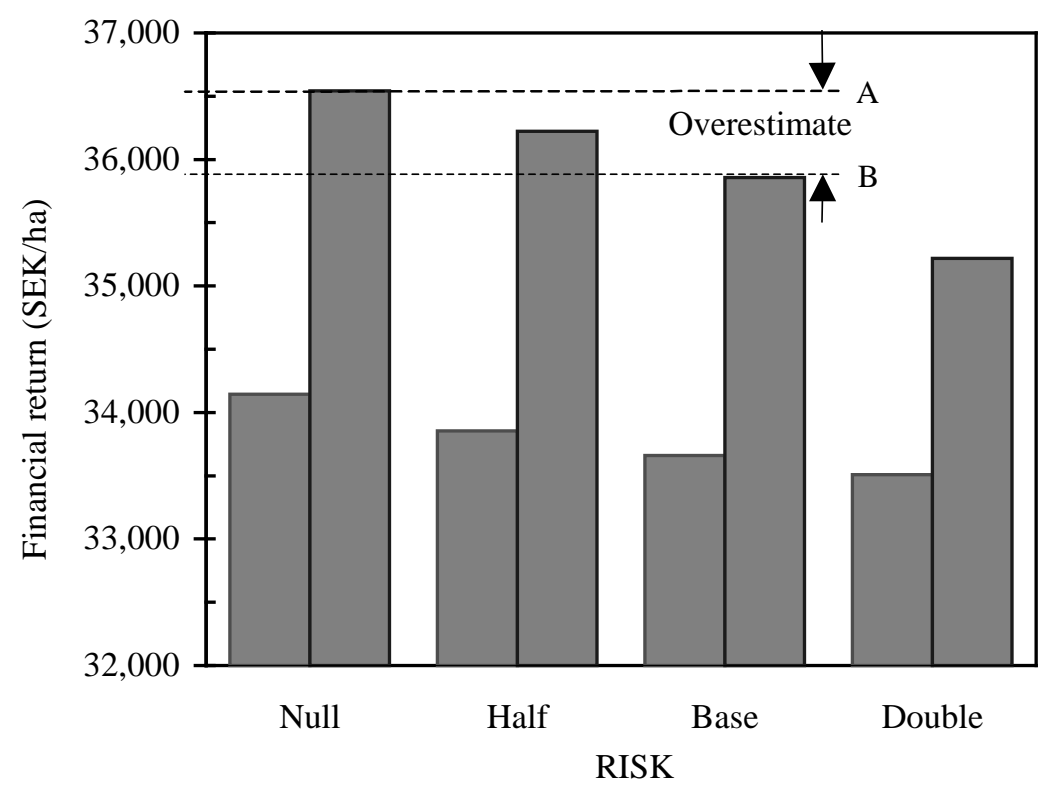

$\square$ Planting method $\quad \square$ Seed-tree method

Figure 4. Impacts of risk degrees on the financial return and the choice of regeneration methods 